\title{
Measurement of lung tissue mass in Pneumocystis carinii pneumonia
}

\author{
D J SEDDON, P D SNASHALL \\ From the Department of Medicine, Charing Cross Hospital, London
}

ABSTRACT Transmission-emission scanning of the thorax with a flood source of technetium-99m $\left({ }^{99 \mathrm{~m}} \mathrm{Tc}\right)$, autologous ${ }^{99 \mathrm{~m}} \mathrm{Tc}$ labelled red blood cells, and diethylenetriaminepenta-acetic acid $\left({ }^{99 \mathrm{~m}} \mathrm{~T} \mathrm{C}_{\mathrm{O}}\right.$ DTPA) allows measurement of thoracic tissue thickness and blood and interstitial volume per pixel of the gamma camera image. Volume of blood or interstitium per pixel divided by pixel area gives the thoracic tissue thickness for these two compartments. A measure of lung tissue thickness may be obtained by subtracting chest wall thickness as measured on a lateral chest radiograph. As part of the $\vec{D}$ evaluation of this technique 13 patients were scanned before treatment for proved or presumed pneumocystis pneumonia and their results were compared with those of 12 normal young men, approximately matched for age. In the patients with pneumocystis pneumonia lung tissue thickness at $\vec{\bullet}$ the base of the right lung averaged $3.4 \mathrm{~cm}(71 \%)$ more than that in the normal subjects, and interstitialo thickness was $1.2 \mathrm{~cm}(150 \%)$ more than in the normal subjects. After treatment 10 of the patients with pneumocystis pneumonia were scanned again. Lung tissue thickness remained greater than the control value by $1.2 \mathrm{~cm}$ and interstitial tissue thickness by $0.5 \mathrm{~cm}$. Blood thickness remained unchanged. Lung tissue and interstitial tissue thickness was correlated with a numerical score of the changes in the chest radiograph. The changes in the properties of the lung tissue compartments in the $e_{\Omega}^{\infty}$ patients presumably reflect the mural and intra-alveolar inflammation found in pneumocystis pneumonia. Transmission scanning alone measures the increase of lung tissue thickness as well as 3 transmission-emission scanning. It may be of value in monitoring the progress of this condition during treatment.

\section{Introduction}

We have recently described a new technique for estimating tissue mass using a gamma camera. ${ }^{1}$ In transmission scanning gamma rays are passed through the thorax and by measurement of the attenuation of the gamma rays the thickness of attenuating tissue can be calculated. Lung tissue thickness is increased in interstitial lung disease and decreased in emphysema. After a transmission scan has been performed the patient's blood is labelled with a gamma ray emitting isotope, and the emission of gamma rays from the thorax is measured, with a correction for attenuation based on data derived from the transmission scan. With suitable calibration the volume of blood in each pixel of the gamma camera image can be determined from the counts per millilitre of blood. Finally, the extracellular fluid is labelled, and after a suitable time

Address for reprint requests: Dr David Seddon, Department of Medicine, Charing Cross Hospital, London W6 8RF.

Accepted 26 May 1989 for equilibration values for thoracic interstitial fiuid $\underset{x}{\stackrel{0}{0}}$ volume for each pixel are derived.

As part of the evaluation of this technique, we have? studied patients with Pneumocystis carinii pneumonia. This disease is usually characterised by increased 3 opacification of the chest radiograph, and we couldo compare findings before and after treatment. Our hypothesis was that transmission-emission scanninge may supplement the radiological information, firstly, by giving precise measurements of the extent of abnormal pulmonary shadowing and, secondly, by allowing images of abnormal tissue to be resolved into intravascular and interstitial compartments.

\section{Methods}

PATIENTS

Thirteen patients with human immunodeficiency virus (HIV) related respiratory illness agreed to be scanned as part of their investigation and assessment. They⿳亠口冋 were aged 33-61 (mean 39) years. The mean height waso $177 \mathrm{~cm}$ and weight $70 \mathrm{~kg}$. All were admitted to hospital 
with typical clinical and radiographic features of pneumocystis pneumonia. Hypoxaemia at rest was present in all cases, but bronchial washings showed cysts of $P$ carinii in only four of the seven patients who had bronchoalveolar lavage. In the remaining patients clinical and radiological features together with response to treatment were taken as indicating pneumocystis pneumonia. Treatment with either high dose co-trimoxazole or pentamidine produced clinical and radiographic improvement in all patients. In no instance was any other microbiological cause for the pneumonia found. None of the patients abused intravenous drugs.

All transmission-emission scans were performed after the start of treatment but within seven days of presentation. Ten patients were restudied one to three months later.

Scans were also performed on 12 healthy male volunteers, who were all members of hospital staff of similar age, height, and weight. There was no evidence of lung disease in any of these subjects.

All subjects gave their informed consent for inclusion in this study, which was approved by the ethical committee of Charing Cross Hospital.

\section{SCANNING}

With minor modifications, our scanning techniques were the same as those previously described and validated.' Briefly the method is as follows.

Transmission scanning was performed with a flood source consisting of a perspex container filled with an aqueous solution of $25 \mathrm{mCi}$ of technetium- $99 \mathrm{~m}\left({ }^{99 \mathrm{~m}} \mathrm{Tc}\right)$ labelled pertechnetate. This was scanned with a gamma camera (Scintag, NE 8900, Nuclear Enterprises) for two minutes to obtain unattenuated flood source counts (Io). The subject was then seated facing the flood source and with his back to the gamma camera, and a further two minute scan was performed, the counts this time representing gamma rays attenuated by their passage through the thorax (I). The attenuation of gamma rays depends on tissue thickness $(x)$ and the linear attenuation coefficient $(\mu)$. Thus

$$
\mathrm{I} / \mathrm{Io}=\mathrm{e}^{-\mu x} \text {. }
$$

The flood source was then removed and a commercially available bone scan kit (Osteolite, Amersham, UK) containing $0.34 \mathrm{mg}$ stannous fluoride was reconstituted and injected to prepare the erythrocytes for ${ }^{99} \mathrm{~m}$ Tc labelling. ${ }^{2}$ Ten minutes later $10 \mathrm{ml}$ of blood was withdrawn into a syringe containing $3 \mathrm{mCi}$ of ${ }^{99 \mathrm{~m}} \mathrm{Tc}$ pertechnetate. With this technique there was always at least $90 \%$ binding of ${ }^{99 m} \mathrm{Tc}$ to the red blood cells. The labelled blood was then reinjected into the patient. A further emission scan was then recorded for two minutes, starting eight minutes after reinjection.

During the scan a $6 \mathrm{ml}$ blood sample was taken to measure ${ }^{y m_{m}} \mathrm{Tc}$ activity in whole blood and plasma in a well counter, and to measure packed cell volume; 7 $\mathrm{mCi}$ of ${ }^{99 \mathrm{~m}} \mathrm{Tc}$ DTPA was then injected to label the extravascular compartment, followed by scanning for a further two minutes, starting three minutes after the injection. During this period a further $6 \mathrm{ml}$ blood sample was taken to measure whole blood and plasma radioactivity. To obtain a scan of ${ }^{99 m}$ Tc DTPA free of counts from ${ }^{99_{\mathrm{m}}} \mathrm{Tc}$ labelled erythrocytes we subtract the stored blood image from the composite image.

Emission scans are corrected for attenuation by means of the formula

$$
E_{\mathrm{o}}=\frac{E \mu x}{\left(1-\mathrm{e}^{-\mu x}\right)},
$$

where $E$ is the measured activity from the thorax, and $E$ o the total unattenuated counts. The $\mu x$ used in the equation is derived from the transmission scan. ' Blood volume was calculated on the basis of the ${ }^{99 m} \mathrm{Tc}$ erythrocyte counts from the blood taken at the time of scanning, on the assumption that thoracic blood packed cell volume is 0.9 of peripheral venous packed cell volume. ${ }^{3}$ Interstitial volume was obtained by subtracting calculated plasma volume from ${ }^{99 m} \mathrm{Tc}$ DTPA distribution volume. A computer program was used to select regions of interest from apex to base down the central regions of both lung fields. Analysis was performed on each pixel of the gamma camera view. Blood volume and interstitial volume divided by pixel area $\left(0.64 \mathrm{~cm}^{2}\right)$ give a value for the "thickness" of these compartments.

After scanning, posteroanterior and lateral chest radiographs were taken with radio-opaque markers attached to the skin. Chest wall thickness was measured from the lateral radiograph. Thoracic tissue thickness, blood thickness, and interstitial tissue thickness were measured at four levels in the lower half of the right lung. Chest wall thickness was subtracted from thoracic tissue thickness to give lung tissue thickness.

We assessed the appearance of the chest radiograph at the time of scanning using a semiquantitative scoring system (table 1). The radiograph was given a number on the basis of the extent and density of parenchymal lung shadowing. The films were coded before being read by one of us, so that the radiographic information was unbiased by knowledge of the scan itself.

\section{STATISTICAL ANALYSIS}

Paired and unpaired $t$ tests were used to assess the significance of the results of the transmission-emission scans. Spearman's test of ranked non-parametric correlation was used to determine the degree of relationship between lung tissue thickness and interstitial thickness and radiographic score. 
Table 1 Radiographic assessment of pneumocystis pneumonia

\begin{tabular}{lll}
\hline & Score & $\begin{array}{l}\text { No of } \\
\text { patients }\end{array}$ \\
\hline $\begin{array}{ll}\text { Perihilar lung shadowing } \\
\text { Vague }\end{array}$ & 1 & 0 \\
Definite & 2 & 0 \\
Dense & 3 & 0 \\
Dense with air bronchogram & 4 & 2 \\
Shadowing throughout lung field & & \\
Vague & 3 & 3 \\
Definite & 4 & 3 \\
Dense & 5 & 1 \\
Dense with air bronchogram & 6 & 4 \\
\hline
\end{tabular}

\section{Results}

The results for each subject are shown in table 2 and those for each group in table 3. Thoracic tissue thickness was increased by $2.6 \mathrm{~cm}$, blood thickness by $3.4 \mathrm{~cm}$, and interstitial thickness by $1.2 \mathrm{~cm}$ in the 13 patients with pneumocystis pneumonia by comparison with values in 12 normal subjects.

Table 2 Initial scanning* values for thoracic, lung, and interstitial tissue thickness ( $T t, T l, T$ in) and bronchoscopy findings in patients with Pneumocystis carinii pneumonia

\begin{tabular}{llllll}
\hline $\begin{array}{l}\text { Patient } \\
\text { No }\end{array}$ & $\begin{array}{l}T t \\
(\mathrm{~cm})\end{array}$ & $\begin{array}{l}T l \\
(\mathrm{~cm})\end{array}$ & $\begin{array}{l}\text { Tin } \\
(\mathrm{cm})\end{array}$ & $\begin{array}{l}\text { Days to } \\
\text { scant }\end{array}$ & $\begin{array}{l}\text { P carinii } \\
\text { in bronchial } \\
\text { washings }\end{array}$ \\
\hline 1 & 9.7 & 6.3 & 2.4 & 7 & - \\
2 & 10.8 & 6.8 & 1.9 & 1 & No \\
3 & 14.9 & 11.9 & 2 & 6 & - \\
4 & 13.2 & 9.2 & 2.3 & 5 & - \\
5 & 12.5 & 9.3 & 3.2 & 1 & - \\
6 & 9.5 & 5.8 & 1.6 & 2 & Yes \\
7 & 10.5 & 6.5 & 2 & 4 & No \\
8 & 13.1 & 9.1 & 1.7 & 1 & No \\
9 & 12.5 & 8 & 1.2 & 1 & Yes \\
10 & 10.3 & 6.3 & - & 2 & Yes \\
11 & 12.7 & 7.9 & 1.3 & 6 & Yes \\
12 & 17.6 & 12.3 & - & 2 & - \\
13 & 11.4 & 7.4 & - & 2 & - \\
\hline
\end{tabular}

*Three patients $(10,12$, and 13$)$ had transmission scans only. †From start of treatment to scanning.
NORMAL SUBJECTS

About $55 \%$ of the gamma ray attenuating tissue in the anteroposterior plane was in the chest wall. Bloode thickness was greater at the base of the lung than at the apex. No such gradient was found for interstitial tissue thickness (fig la). At the base of the right lung mean? (SD) blood thickness was $2.3(0.6) \mathrm{cm}(48 \%$ of lungs tissue thickness) and interstitial tissue thickness 0.85 $(0 \cdot 2) \mathrm{cm}$ (17\% of lung tissue thickness).

\section{PATIENTS WITH PNEUMOCYSTIS PNEUMONIA}

At the initial scanning thoracic tissue thickness was $12 \cdot 2(2 \cdot 3) \mathrm{cm}$, lung tissue thickness $8 \cdot 2(2 \cdot 1) \mathrm{cm}$, and interstitial tissue thickness $2.0(0.6) \mathrm{cm}$. Interstitiapo tissue thickness was equal to or greater than blood thickness throughout the length of the lung (fig $1 b$ ).

After treatment lung tissue mass was significantly $\supset$ smaller $(\mathrm{p}<0.01)$ than before treatment (fig 2) $\vec{\square}$ Interstitial tissue thickness at the base of the lung was now less than blood thickness (fig 1c), but remained significantly greater than in normal subjects (table 3$). \stackrel{\text { ? }}{+}$

The radiograph score showed a significant andeo positive correlation with lung tissue thickness $(p<0$ $0.05)$ and interstitial thickness $(\mathrm{p}<0.05)$ (figs $3 a$ and $3 b$ ) but no significant correlation with blood thickness.

\section{Discussion}

In patients with pneumocystis pneumonia who have an abnormal chest radiograph we have shown that tissue thickness (in the anteroposterior plane) was $2.6_{5}$ $\mathrm{cm}(27 \%)$ greater in the lower lung zone than in age matched normal subjects. We also found an increase in extravascular ${ }^{99}$ Tc DTPA distribution volume, sug -0 gesting that some of the radiological opacification is due to an increase in extracellular and extravascular lung water. These changes in tissue and interstitia $B$. tissue thickness correlated with a numerical scoring of the chest radiograph. Blood thickness was normal.3 The technique uses readily available equipment ando reagents and was acceptable to the patients. There were no complaints or complications.

Technetium-99m DTPA is a small hydrophilic molecule that is distributed with extracellular fluid. Ito

Table 3 Mean (SD) thickness of transthoracic tissue compartments in the normal subjects and patients with Pneumocystis carinii pneumonia

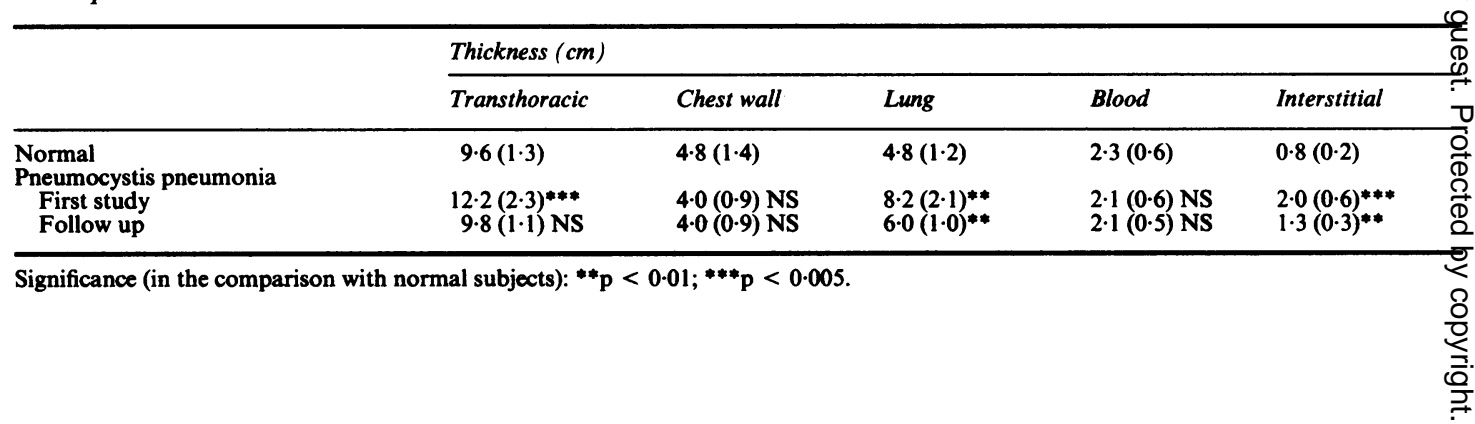



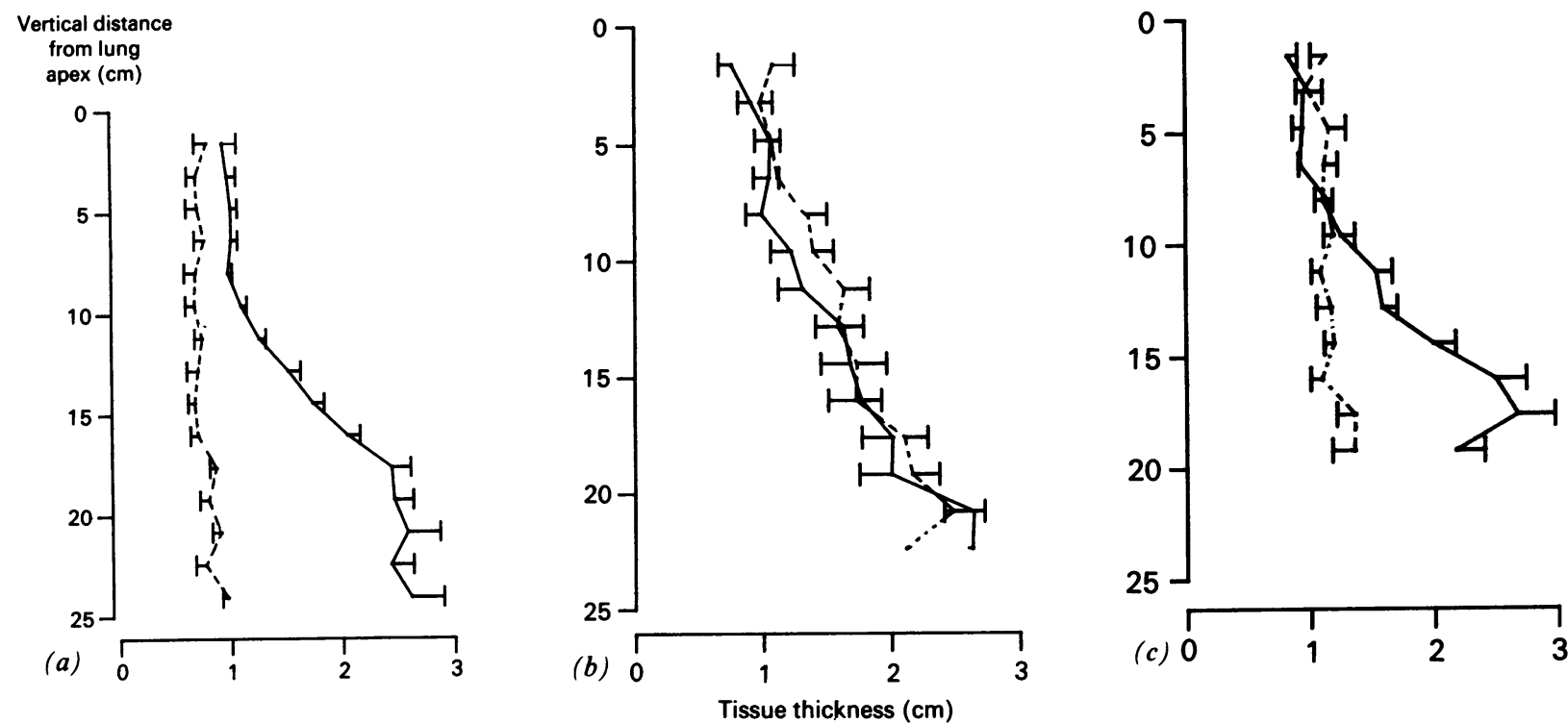

Fig 1 Thoracic blood (__ ) and interstitial (- - -) thickness from apex to base of the right lung in (a) 12 normal subjects; (b) 10 patients with pneumocystis pneumonia; (c) 10 patients with pneumocystis pneumonia after completion of treatment. Bars indicate 1 SEM.

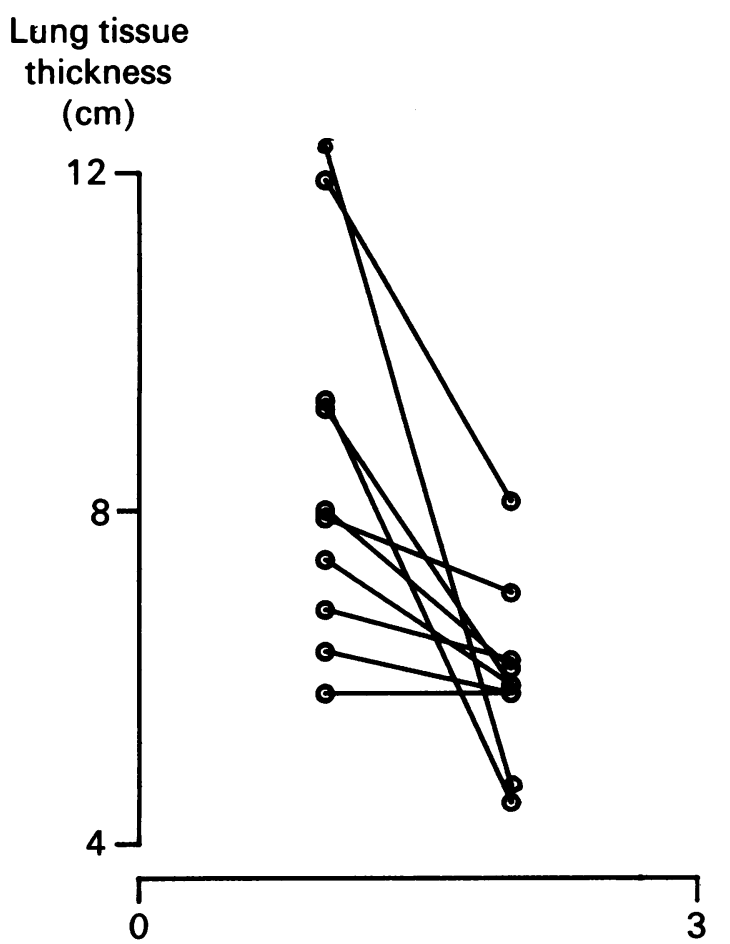

Before

After

Fig 2 Lung tissue thickness in pneumocystis pneumonia before and after the completion of treatment $(p<0.01)$. does not enter cells to any appreciable extent. Molecules of this size readily cross lung capillary endothelium and rapidly appear in lung lymph, reaching the same concentration in lymph as in plasma. ${ }^{99 m}$ Tc DTPA is, however, restricted in its passage across alveolar epithelium. In normal non-smoking individuals the half time of the diffusion of ${ }^{99 m} \mathrm{Tc}$ DTPA across alveolar epithelium is about 60 minutes, but this is reduced to about two minutes in pneumocystis pneumonia. ${ }^{5-7}$ Pathologically pneumocystis pneumonia is characterised by disruption of the alveolar epithelium, an alveolar luminal exudate, and inflammation of the septal interstitium. ${ }^{89}$ In the presence of this epithelial damage, ${ }^{99 m}$ Tc DTPA might be expected to cross the alveolar epithelium and equilibrate with interstitial exudate within the five minutes between injection and scanning. The isotope will also equilibrate with inflammatory exudate in the alveolar septal interstitium. Interestingly, in cardiogenic pulmonary oedema, in which we believe the alveolar epithelial barrier to be intact, we have observed only modest increases in ${ }^{99 m}$ Tc DTPA space despite obvious radiographic changes and large increases in thoracic tissue thickness. In sarcoidosis and fibrosing alveolitis varying increases of interstitial tissue thickness are seen, ${ }^{1}$ presumably owing to alveolar septal inflammation, and this may depend on disease activity.

The comparison of scanning and radiographic changes suggests that the increase in lung tissue due to pneumonia may be quantified just as well by the simple 


\section{(a) Lung tissue \\ thickness \\ (cm)}

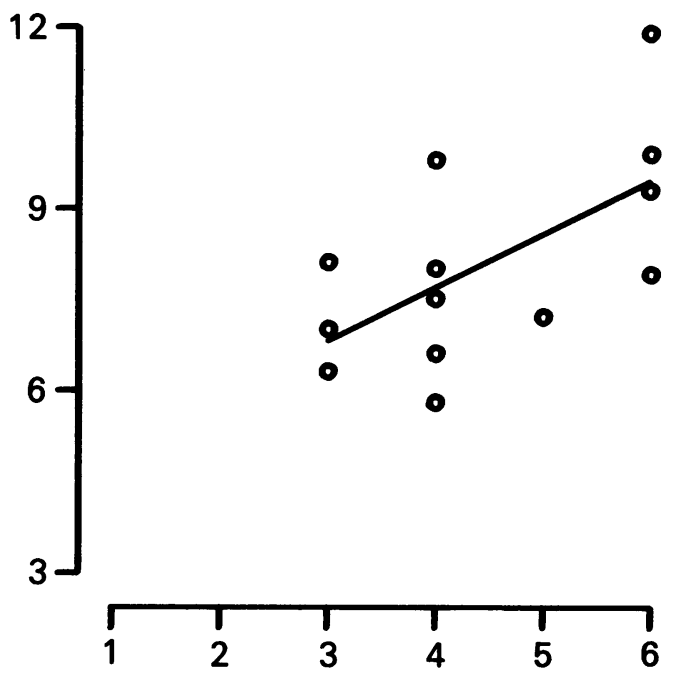

(b) Interstitial

thickness

(cm)

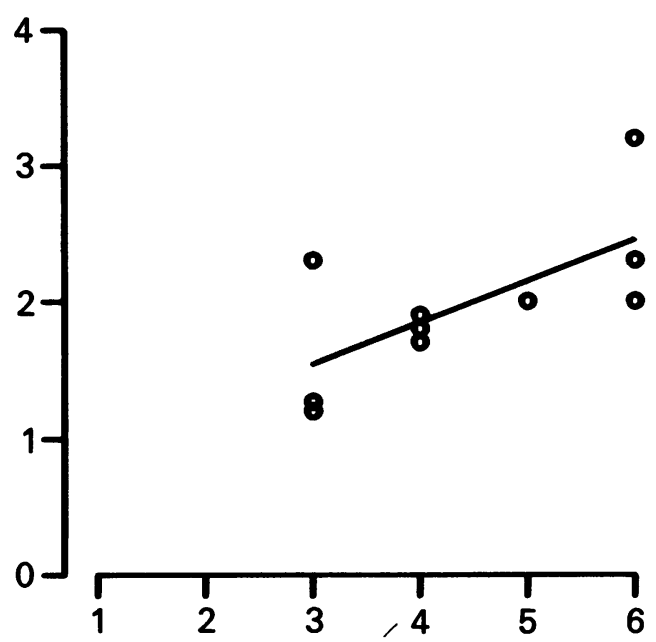

Radiographic score

Fig 3 Radiographic assessment (see table 1) of pneumocystis pneumonia against $(a)$ lung tissue thickness ( $r=0.62$, $p<0.05 ; n=13)$ and (b) interstitial tissue thickness $(r=0.67, p<0.05 ; n=10)$.

technique of transmission scanning as by the more complex transmission-emission technique. The absorbed dose of radiation from transmission scanning is minute (about $0.002 \mathrm{mSv}$ ) by comparison with transmission-emission scanning $(1.2 \mathrm{mSv}$-approximately equivalent in terms of the marrow and gonadal dose to one abdominal radiograph). Transmission scanning takes only two minutes, needs no intravenous injections, and simply requires that the patient remains seated in the same position. It may therefore have a role in monitoring disease progress during treatment.

DJS is supported by the Medical Research Council.

\section{References}

1 Briggs BA, Bradley TM, Vernon P, et al. Measurement of lung tissue mass, thoracic blood and interstitial volumes by transmission/emission scanning using [99m-Tc] pertechnetate. Clin Sci 1987;73:319-27.

2 Popescu HI, Lessem J, Erjavec M, Fuger GF. In vivo labelling of RBC with $99 \mathrm{~m}$-Tc for blood imaging using different stannous radiopharmaceuticals. Eur $J$ Nucl Med 1984;9:295-9.

3 Brudin LH, Valind SO, Rhodes CG, Turton DR, Hughes JMB. Regional lung hematocrit in humans using positron emission tomography. J Appl Physiol 1986;60:1155-63.

4 Snashall PD, Keyes SJ, Morgan B, Jones B, Murphy K. Regional extravascular and interstitial lung water in normal dogs. J Appl Physiol 1980;49:547-51.

5 Barrowcliffe MP, Jones JG. Solute permeability of the alveolar capillary barrier. Thorax 1987;42:1-10.

6 O'Doherty MJ, Page CJ, Bradbeer CS, et al. Alveolar permeability in HIV antibody positive patients with Pneumocystis carinii pneumonia. Genitourin Med 1987;63:268-70.

7 Mason GR, Duane GB, Mena I, Effros RM. Accelerated solute clearance in Pneumocystis carinii pneumonia. Am Rev Respir Dis 1987;135:864-8.

8 Yoneda K, Walzer PD. Mechanism of pulmonary alveolar injury in experimental Pneumocystis carinii pneumonia in the rat. Br J Exp Pathol 1981;62:339-46.

9 Hasleton PS, Curry A, Rankin EM. Pneumocystis carinii pneumonia: a light microscopical and ultrastructural study. J Clin Pathol 1981;34:1138-46. 